\title{
Aldolase C/Zebrin II Expression in the Neonatal Rat Forebrain Reveals Cellular Heterogeneity within the Subventricular Zone and Early Astrocyte Differentiation
}

\author{
Susan M. Staugaitis, ${ }^{1}$ Marielba Zerlin,, ${ }^{2}$ Richard Hawkes, ${ }^{3}$ Joel M. Levine, ${ }^{4}$ and James E. Goldman ${ }^{2}$ \\ ${ }^{1}$ Department of Neurosciences (NC30), The Lerner Research Institute, The Cleveland Clinic Foundation, Cleveland, Ohio \\ 44195, 2Department of Pathology, Columbia University, College of Physicians and Surgeons, New York, New York 10032, \\ ${ }^{3}$ Department of Cell Biology and Anatomy, Faculty of Medicine, University of Calgary, Alberta, Canada, T2N 4N1, and \\ ${ }^{4}$ Department of Neurobiology and Behavior, State University of New York, Stony Brook, New York 11794
}

During late gestational and early postnatal development, proliferating cells in the subventricular zones of the lateral ventricles (SVZ) migrate into the gray and white matter of the forebrain and differentiate into astrocytes and oligodendrocytes. Because the cellular composition and structure of the neonatal SVZ is poorly understood, we performed a differential display PCR screen to identify genes preferentially expressed therein. One highly expressed gene encoded aldolase C. We used a specific monoclonal antibody, aldolase C/zebrin II (ALDC/ ZII), in combination with markers of glial lineage and proliferation, to characterize the cells that express this gene. In the neonatal SVZ, ALDC/ZII-positive cells, which are generally polygonal and display several processes, have a nonuniform spatial distribution. They do not express vimentin, GFAP, or NG2. A subset of ALDC/ZII-positive cells incorporates bromodeoxyuridine, but progenitors identified by $\beta$ galactosidase expression after infection with recombinant BAG virus do not show ALDC/ZII immunoreactivity. Outside of the SVZ, $\beta$-galactosidase-positive/ALDC/ZII-positive cells have an astrocytic phenotype, suggesting that immunoreactivity was acquired after exit from the SVZ. These studies demonstrate that the neonatal SVZ is composed of different populations of cells that can be characterized by their antigenic phenotype, their proliferative capacity, and their spatial distributions. Nonrandom distributions of different cell types within the SVZ may permit the formation of microenvironments that stimulate the production of cells with specific potentials at appropriate points in development. Analysis of ALDC/ZII expression by astrocyte lineage cells in the neonatal cerebral cortex and white matter may reveal insights into the phenotype and behavior of undifferentiated astrocyte progenitors.

Key words: subventricular zone; astrocyte; oligodendrocyte; progenitor cells; cell lineage; aldolase C; zebrin II; NG2 chondroitin sulfate proteoglycan; vimentin
During late gestational and early postnatal development in the mammalian forebrain, there is a marked proliferation and accumulation of cells in the subventricular zones of the lateral ventricles (SVZ) (Privat, 1975). Cycling cells of this zone migrate into the gray and white matter of the forebrain and differentiate into astrocytes and oligodendrocytes (Levison and Goldman, 1993; Zerlin et al., 1995). The cellular composition and structure of the neonatal SVZ is poorly understood, however. Earlier histological observations pointed out two conspicuous cell types, based on nuclear morphology (Smart, 1961): a majority population of cells with small, dark nuclei, sometimes oval or elongated, and a minority population of cells with larger, more lucent nuclei.

One approach to understanding cellular heterogeneity in the $\mathrm{SVZ}$ is to look for genes preferentially expressed therein. To this

\footnotetext{
Received Jan. 23, 2001; revised May 30, 2001; accepted June 5, 2001.

This work was supported by National Institutes of Health (NIH) Grant NS 17125 (J.E.G.) and Lerner Research Institute Seed Support (S.M.S.). The Confocal Microscopy Facility was established by NIH Shared Instrumentation Grant 1S10 RR10506 and is supported by NIH Grant 5 P30 CA13696 as part of the Herbert Irving Cancer Center at Columbia University (Dr. Liza Pon, Director; Theresa C. Swayne, Manager). The technical assistance of Lina Hurwitz and Raimonda Kopelnitsky is greatly appreciated. This paper is dedicated to the memory of Helen and Ed Staugaitis.

Correspondence should be addressed to Dr. Susan M. Staugaitis, Department of Neurosciences (NC30), The Lerner Research Institute, The Cleveland Clinic Foundation, 9500 Euclid Avenue, Cleveland, OH 44195. E-mail: staugas@ccf.org. Copyright (ㄷ) 2001 Society for Neuroscience $0270-6474 / 01 / 216195-11 \$ 15.00 / 0$
}

end, we have performed a differential display PCR screen to identify mRNAs highly expressed in the neonatal SVZ. One of the clones encoded a partial sequence for aldolase $\mathrm{C}$ /zebrin II (ALDC/ZII). Aldolase $\mathrm{C}$ is the brain-specific isoform of fructose-1,6-bisphosphate aldolase (EC 4.1.2.13) (Lebherz and Rutter, 1969). Aldolase C mRNA is expressed early in embryonic development: studies on Xenopus laevis embryos show that expression increases markedly during late neurulation (Yatsuki et al., 1998), and periventricular ALDC/ZII-positive cells have been identified throughout the neuroaxis of mice from embryonic day 14 (E14) to postnatal day 7 (P7) (R. Hawkes, unpublished data). Immunostaining of adult human and rodent tissues show intense staining in certain neuronal populations, particularly Purkinje cells. Weak staining of astrocytes has also been described (Thompson et al., 1982; Kumanishi et al., 1985; Brochu et al., 1990). Zebrin II is an antigen recognized by a monoclonal antibody raised to a cerebellar homogenate from the electric fish (Brochu et al., 1990). ZII first appears in rodent Purkinje cells in the vermis at P5, is widely expressed by P12, but after P15, the expression is reduced in a subpopulation of Purkinje cells. In the adult, ZII is expressed by Purkinje cells in parasagittal stripes (Brochu et al., 1990). cDNA cloning demonstrated that ZII was identical to ALDC (Ahn et al., 1994). More recently, transgenic mouse lines expressing LacZ under the control of the ALDC/ZII 
promoter showed expression of the transgene in glial cells (Arai et al., 1994; Walther et al., 1998).

We observe that ALDC/ZII is expressed in the neonatal rat SVZ by large, polygonal or elongated cells that have a nonuniform spatial distribution and display a morphology that is distinct from that of the smaller, unipolar, cycling progenitors that migrate out of this region to become forebrain glia. However, ALDC/ZII immunoreactivity is acquired by some migrating progenitors after they exit from the SVZ, apparently as an early marker of astrocyte, but not oligodendrocyte, differentiation.

\section{MATERIALS AND METHODS}

Animals. Animals were cared for in accordance with the Society for Neuroscience Policy on the Use of Animals in Neuroscience Research. $\mathrm{P} 0-\mathrm{P} 2$ rats were used for dissection of the SVZ because this region is the largest at this age. Gene expression analysis was performed on rats of age P5-P7, so that both immature SVZ progenitor cells and differentiating forebrain glia could be examined simultaneously.

Tissue dissection. $\mathrm{P} 0-\mathrm{P} 2$ rat pups were anesthetized by hypothermia. Their brains were removed and chilled in PBS. The leptomeninges were dissected off of the forebrain and solubilized in Tripure reagent (Boehringer Mannheim, Indianapolis, IN). Three hundred micrometer sections of forebrain were cut using a vibratome and collected into cold PBS. The SVZ and adjacent corpus striatum were separately dissected under phase optics and were collected into cold PBS. After collecting tissues from four brains, the tissue was pelleted, PBS was removed, and $0.2 \mathrm{ml}$ Tripure reagent was added. The tissue was dissociated by gentle vortex and stored at $-70^{\circ} \mathrm{C}$ until use. The purity of the SVZ preparations was assessed by microscopic examination of hematoxylin and eosin-stained paraffin sections of a representative preparation. The specimen contained $>95 \%$ SVZ. Contaminating tissues included subcortical white matter and ependyma. RNA from adult cortex and white matter was prepared by homogenization in guanidine $\mathrm{HCl}$ and centrifugation through cesium chloride and resuspended in water (Sambrook et al., 1992). Oligodendrocyte progenitor cultures and cultured meningeal fibroblasts were rinsed once in PBS and then suspended in Tripure reagent $\left(2 \mathrm{ml} / 25 \mathrm{~cm}^{2}\right.$ flask).

Cell cultures. Culture media components were obtained from the following sources: base media, fetal calf serum, and antibiotics (Life Technologies, Rockville, MD); insulin, selenium, and transferrin mixture (Collaborative Research/BD Biosciences, San Diego, CA); leucine methyl ester, poly-L-lysine, transferrin, progesterone, biotin, and putrescine (Sigma, St. Louis, MO); PDGF AA and basic fibroblast growth factor (bFGF) (Boehringer Mannheim). Oligodendrocyte progenitor cultures were prepared according to the procedure established by McCarthy and DeVellis (1980) and Levison et al. (1990). Mixed glial cultures were prepared by dissociation of $\mathrm{P} 0$ forebrain in $0.125 \%$ trypsin and $0.1 \mathrm{mg} / \mathrm{ml}$ DNase and filtration through $145 \mu \mathrm{m}$ Nytex filters. The cells $(5 \times$ $10^{7} / \mathrm{T} 75$ flask) were plated in MEM with $10 \% \mathrm{FCS}$ at $5 \% \mathrm{CO}_{2}$ for 1 week. The flasks were shaken at $260 \mathrm{rpm}$ for $1 \mathrm{hr}$, the medium was changed, and the flasks were shaken overnight. Microglia were eliminated by incubation of the medium in $25 \mathrm{~mm}$ leucine methyl ester $\left(37^{\circ} \mathrm{C} \times 20 \mathrm{~min}\right.$; gentle agitation every $\left.5 \mathrm{~min}\right)$ (Ward et al., 1991). The surviving cells were suspended in DMEM with $10 \%$ fetal calf serum and plated onto poly-L-lysine-coated $25 \mathrm{~cm}^{2}$ flasks at a density of $10^{4} / \mathrm{cm}^{2}$. Two hours later, the medium was changed to modified N1B medium [DMEM supplemented with $0.5 \%$ fetal bovine serum, insulin $(5 \mu \mathrm{g} / \mathrm{ml})$, selenium $(5 \mathrm{ng} / \mathrm{ml})$, transferrin $(45 \mu \mathrm{g} / \mathrm{ml})$, progesterone $(20 \mathrm{nM})$, biotin $(10 \mu \mathrm{g} / \mathrm{ml})$, putrescine $(100 \mu \mathrm{M})$, PDGF AA $(10 \mathrm{ng} / \mathrm{ml})$, and bFGF $(10$ $\mathrm{ng} / \mathrm{ml})]$. Cells were harvested for RNA preparation after $1 \mathrm{~d}$ in culture. Portions of each preparation were plated onto poly-L-lysine $(10 \mu \mathrm{g} / \mathrm{ml})$ coated multiwell slides (Shandon, Pittsburgh, PA) and used for immunotyping. After $1 \mathrm{~d}$ in culture these cells were largely positive for A2B5 and GD3. A subpopulation $(\sim 30 \%)$ was O4-positive. Less than $1 \%$ was positive for GFAP, O1, or ED1 (data not shown).

$R N A$ preparation. RNA was prepared from Tripure suspensions according to manufacturer's recommendations. Total RNA $(2-15 \mu \mathrm{g})$ was treated with $30 \mathrm{U}$ of RNase-free DNase (Boehringer Mannheim) in 50 mM Tris $\mathrm{HCl}, \mathrm{pH} 8,20 \mathrm{~mm} \mathrm{MgCl}_{2}$, for $15 \mathrm{~min}$ at $37^{\circ} \mathrm{C}$. The reaction was stopped by incubation for $10 \mathrm{~min}$ at $90^{\circ} \mathrm{C}$, extracted twice each with phenol-chloroform and chloroform, precipitated with ethanol, and resuspended in a small volume of water. RNA was quantified by absorbance at $260 \mathrm{~nm}$, and the concentration was adjusted to $250 \mathrm{ng} / \mu \mathrm{l}$.

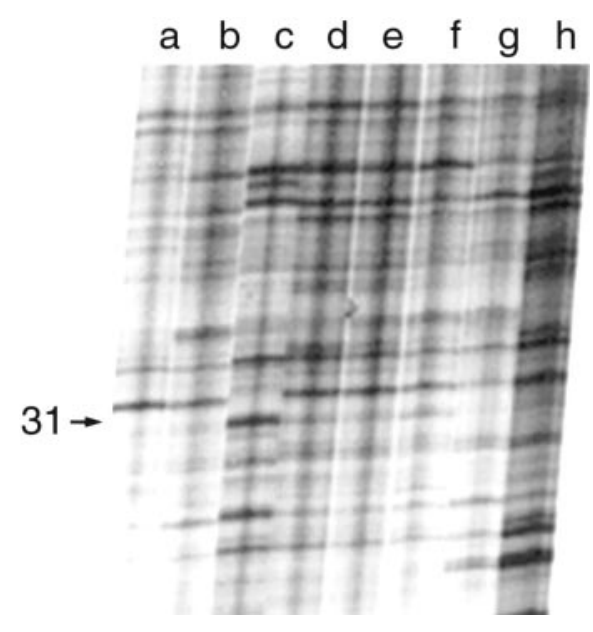

Figure 1. Differential display PCR. Portion of autoradiogram demonstrating partial cDNAs amplified by reverse transcription and random arbitrary primed PCR of total RNA from cultured primary leptomeningeal fibroblasts $(a)$, leptomeninges $(b)$, neonatal SVZ $(c)$, cultured oligodendrocyte progenitor cells $(d-f)$, neonatal striatum $(g)$, and adult cortex and subcortical white matter $(h)$. Band 31 has a mobility of $\sim 350$ bp and is highly enriched in reactions obtained from SVZ RNA compared with the other sources. Sequence analysis showed that the cDNA in this band is $97 \%$ identical to nucleotides 1091-1442 of aldolase C (Kukita et al., 1988).

Random arbitrary primed PCR (differential display PCR). Random arbitrary primed PCR was modified from the procedure of Welsh et al. (1992). Reverse transcriptase (RT) reactions were performed on $250 \mathrm{ng}$ of RNA using $100 \mathrm{U}$ of Moloney murine leukemia virus reverse transcriptase (Promega, Madison, WI) in $50 \mathrm{~mm}$ Tris $\mathrm{HCl}, \mathrm{pH} 8.3,75 \mathrm{~mm}$ $\mathrm{KCl}, 3 \mathrm{~mm} \mathrm{MgCl} 2,10 \mathrm{~mm}$ DTT, $10 \mu \mathrm{M} \mathrm{dNTP}$, and $2.5 \mu \mathrm{M}$ primer $(10 \mathrm{mer}$ primer; kit AJ; Operon, Alameda, CA), in a $10 \mu$ l final volume. Three microliters of RT reaction was used for each PCR in a $6 \mu$ l final volume. The final concentrations of reagents were: second 10 mer primer, 1.25 $\mu \mathrm{M} ;$ Taq polymerase (Fisher Scientific, Pittsburgh, PA), $2.5 \mathrm{U}$; $\left[{ }^{33} \mathrm{P}\right] \mathrm{dATP}, 3000 \mu \mathrm{Ci} / \mathrm{mmol}$ (Amersham Pharmacia Biotech, Piscataway, $\mathrm{NJ}), 2 \mu \mathrm{Ci}$. After the reaction an equal volume of sequencing gel buffer was added, and a portion was electrophoresed through a $6 \%$ denaturing polyacrylamide gel at $1800 \mathrm{~V}$ for 2-4 hr. Gels were dried onto filter paper and exposed to $\mathrm{x}$-ray film. DNA corresponding to bands of interest was extracted from the gels and purified by the crush and soak method (Sambrook et al., 1992). DNA was amplified using the RT-PCR primers. The reaction product was purified through an agarose gel, and the DNA was subcloned into pGEM-TEasy (Promega). DNA sequencing was performed by PCR in the presence of $\left[{ }^{33} \mathrm{P}\right] \mathrm{dATP}$ using the Fmol kit (Promega) and separated as described above. Sequences were screened using the Blast search for nonredundant and dbEST sequences. Band 31 (Fig. 1) was identified as a partial cDNA encoding ALDC/ZII nucleotides 1091-1442 (Kukita et al., 1988).

In situ hybridization. Antisense and sense cRNA probes were prepared according to manufacturer's recommendations starting with $1 \mu \mathrm{g}$ of linearized DNA using SP6 or T7 polymerase (Promega). Probe quality was assessed by agarose electrophoresis and quantified by dot blot.

In situ hybridization was performed according to the procedure of Schaeren-Wiemers and Gerfin-Moser (1993). P7 rats were anesthetized and perfused intracardially with $4 \%$ paraformaldehyde in PBS. Tissue was cryoprotected with $20 \%$ sucrose in PBS and frozen in liquid nitrogen. Ten micrometer cryostat sections were collected onto Superfrost Plus slides (Fisher), baked for $2 \mathrm{hr}$ at $55^{\circ} \mathrm{C}$, and stored at $-70^{\circ} \mathrm{C}$. Slides were pretreated with proteinase $\mathrm{K}(1 \mu \mathrm{g} / \mathrm{ml})$ for $10 \mathrm{~min}$ at $37^{\circ} \mathrm{C}$, post-fixed in $4 \%$ paraformaldehyde for $10 \mathrm{~min}$, and acetylated $(0.25 \%$ acetic anhydride in $0.1 \mathrm{M}$ ethanolamine) for $10 \mathrm{~min}$. Probes were diluted in hybridization buffer (Schaeren-Wiemers and Gerfin-Moser, 1993) containing $0.1 \%$ Triton $\mathrm{X}-100$ under glass coverslips overnight at $72^{\circ} \mathrm{C}$. Sections were rinsed several times with $2 \times$ SSC and then washed in $0.1 \times$ SSC for $1 \mathrm{hr}$ at $72^{\circ} \mathrm{C}$. Sections were equilibrated in Tris-buffered saline (TBS), $\mathrm{pH}$ 7.6, and incubated overnight with alkaline phosphatase-conjugated antidigoxygenin antibody (Boehringer Mannheim; 1:1000 in 10\% goat serum 
and $0.1 \%$ Triton $\mathrm{X}-100)$. After washing, nitroblue-tetrazolium-chloride5-bromo-4-chlor-indolyl-phosphate (NBT-BCIP) (Boehringer Mannheim) in TBS, pH 9.6, $2 \mathrm{mM} \mathrm{MgCl}_{2}$, was applied under glass coverslips. Color development was monitored by light microscopy. Signal for ALDC/ZII was first recognized at 2 or $3 \mathrm{hr}$. Development was permitted to continue for up to $5 \mathrm{~d}$ in some cases. Sections were counterstained with methyl green (Sigma).

In vivo labeling of dividing cells. DNA synthesis by SVZ cells was assessed by incorporation of 5-bromo- $2^{\prime}$-deoxyuridine- 5 ' monophosphate (BrdU; Roche, Indianapolis, IN). P5 rat pups were injected $100 \mathrm{mg}$ $\mathrm{BrdU} / \mathrm{gm}$ body weight 4 and $2 \mathrm{hr}$ before intracardiac perfusion.

Lineage tracing of SVZ cells was assessed by injection of the SVZs of P0 rat pups with the BAG retrovirus (Zerlin et al., 1995). Bilateral injections of $1 \mu \mathrm{l}$ of virus (titer $=10^{6}$ ) were targeted to the SVZ at the level of the septal nuclei. Five days after injection the pups were perfused with $3 \%$ paraformaldehyde $/ 0.5 \%$ glutaraldehyde in PIPES, $\mathrm{pH}$ 6.9. Forty micrometer sections were collected using a vibratome and stored in PBS at $4^{\circ} \mathrm{C}$ until use.

Immunocytochemistry. The following antibodies were used: ZII (1:50; Brochu et al., 1990), vimentin 13.2 (1:50; Sigma), GFAP (ALD10, 1:50; Chiu and Goldman, 1984), NG2 (1:200; Levine and Stallcup, 1987), BrdU (1:10; Amersham), and $\beta$-galactosidase (1:100; Promega). Immunolabeling was performed on $7 \mu \mathrm{m}$ paraffin-embedded sections, $10 \mu \mathrm{m}$ cryostat sections, or $40 \mu \mathrm{m}$ vibratome sections. Paraffin sections were deparaffinized and microwaved for $15 \mathrm{~min}$ in $1 \mathrm{~mm}$ EDTA, $\mathrm{pH} 7.5$ (Morgan et al., 1994). Tissue was blocked using 5\% powdered milk, 3\% BSA, and $0.1 \%$ Triton X-100 for $1 \mathrm{hr}$ at room temperature and incubated in primary antibody overnight at room temperature. Sections were washed in $50 \mathrm{~mm}$ Tris $\mathrm{HCl}, \mathrm{pH} \mathrm{7.6}$, incubated in the appropriate isotype-specific FITC- and tetramethylrhodamine isothiocyanate (TRITC)-conjugated antibodies (Southern Biotechnology Associates, Birmingham, AL) for $1 \mathrm{hr}$ at room temperature, washed, incubated briefly in Hoechst 32258, washed again, and coverslipped in Gelmount (Biomeda, Foster City, CA) containing $2.5 \mathrm{mg} / \mathrm{ml}$ 1,4-diazabicyclo[2.2.2] octane (Sigma). Vibratome and cryostat sections were washed with $50 \mathrm{~mm}$ Tris $\mathrm{HCl}, \mathrm{pH} 7.6$, and incubated twice for $5 \mathrm{~min}$ in boiling $1 \mathrm{~mm}$ EDTA. This procedure was essential for adequate staining with the ZII antibody. Sections were blocked and stained as described above. Before BrdU immunolabeling, sections were stained with antibodies to ALDC/ ZII or NG2, followed by sequential incubations in $2 \mathrm{~N} \mathrm{HCl}$ and $0.1 \mathrm{M}$ sodium borate.

Microscopy and image processing. Conventional fluorescence images were obtained from digitized Ektachrome slides (Sprint Scanner, Polaroid, Wayland, MA) or a digital camera (Optronics, Goleta, CA) and processed using Adobe PhotoShop 5.0. Confocal images were obtained using a Zeiss LSM 410 laser-scanning confocal system attached to a Zeiss Axiovert 100TV inverted microscope (Carl Zeiss, Thornwood, NY). Fluorescence was excited by an argon-krypton laser at $488 \mathrm{~nm}$ (FITC) or $568 \mathrm{~nm}$ (TRITC). A $590 \mathrm{~nm}$ longpass emission filter was used for the red signal, and a 515-540 nm bandpass emission filter was used for the green. Plan-Apochromat $100 \times / 1.4$ NA and Plan-Neofluar $40 \times / 1.3$ NA objectives were used. Images were stored as TIFF files and processed using the Zeiss LSM-PC 3.95 software and Adobe Photoshop 5.0. Projections were made from $z$-series collected at intervals of $1 \mu \mathrm{m}$ by the brightest point method.

\section{RESULTS}

\section{ALDC/ZII mRNA is highly expressed in the neonatal SVZ}

A partial sequence for ALDC/ZII was identified during a screen for genes highly expressed in the SVZ. Random arbitrary primed PCR was performed on total RNA using random 10 mer primers. A 350 bp band was abundant in specimens from neonatal SVZ (Fig. 1, lane $c$ ) but not in RNA from leptomeningeal fibroblasts, neonatal leptomeninges, adjacent striatum, or adult cortex and white matter (Fig. 1, lanes $a, b, g, h$ ). In addition, this RNA was not highly expressed in cultures of oligodendrocyte progenitors grown in defined media for $1 \mathrm{~d}$ in the presence of PDGF AA and bFGF (Fig. 1, lanes $d-f$ ). Partial sequencing of the 350 bp cDNA showed $97 \%$ identity with ALDC/ZII. The cDNA spanned 100 bp of the $3^{\prime}$ coding sequence and $250 \mathrm{bp}$ of $3^{\prime}$ nontranslated region. This region shows no significant homology with aldolase A.
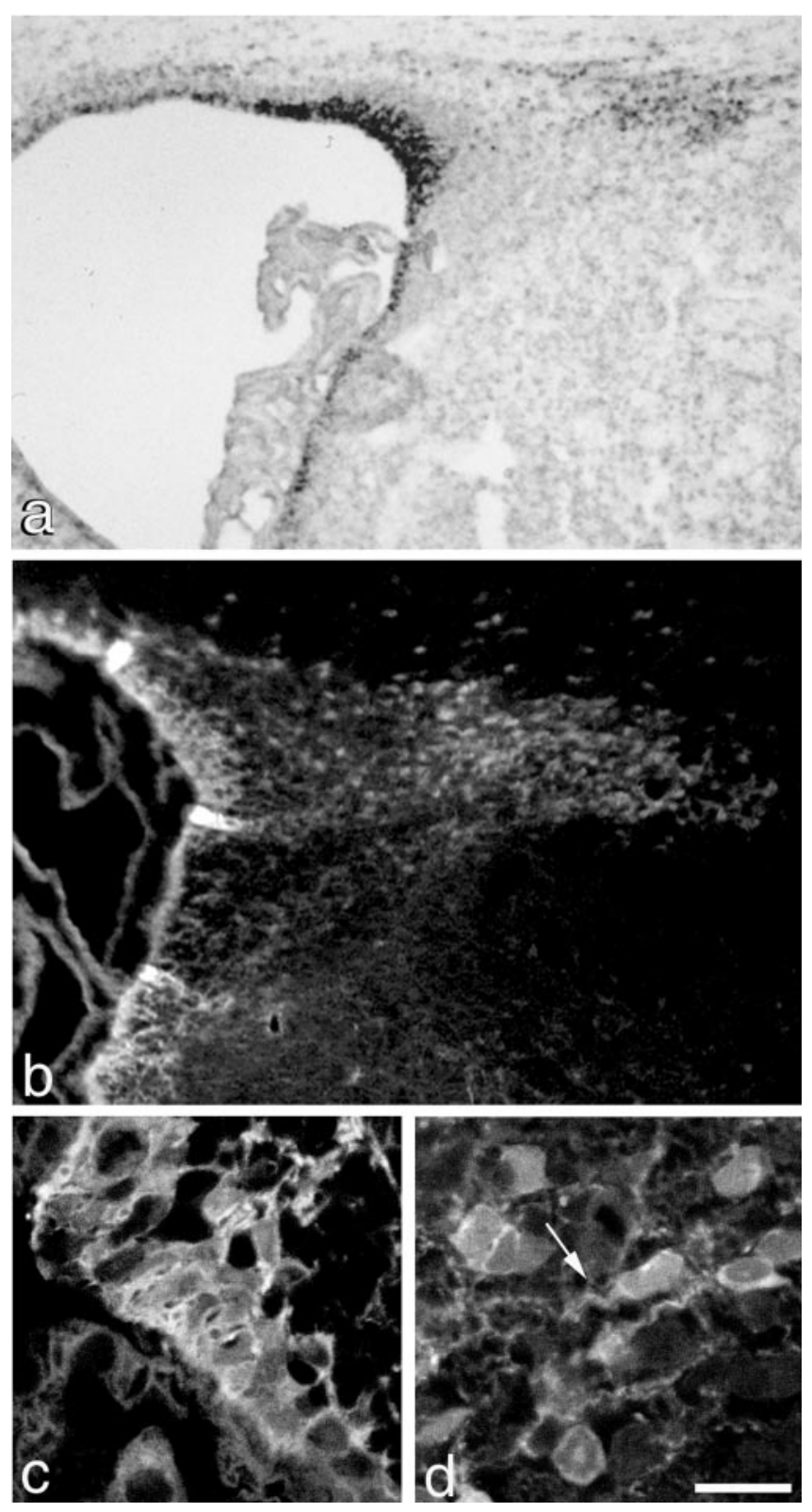

Figure 2. Distribution of ALDC/ZII mRNA and protein in rat P5-P7 SVZ. a, In situ hybridization using digoxygenin-labeled cRNA probe prepared from band 31. Low-power photomicrograph shows the lateral ventricle, SVZ, corpus striatum, and subcortical white matter. Intense staining is seen in cells adjacent to the ventricle and in dense patches of cells at the lateral angle of the ventricle and most dorsolateral aspect of the SVZ. NBT-BCIP with methyl green nuclear counterstain; $10 \mu \mathrm{m}$ cryostat section. $b-d$, Immunofluorescence labeling of SVZ with antibody to ALDC/ZII. $b$, Low-power photomicrograph of SVZ demonstrates a pattern of immunoreactivity similar to that seen by in situ hybridization; $40 \mu \mathrm{m}$ vibratome section. $c$, $d$, Confocal microscopy of ALDC/ZIIpositive cells in the SVZ. $c$, High magnification of ALDC/ZII-positive cells adjacent to the ventricular lumen shows several layers of densely packed labeled cells. $d$, In areas where the cells are less densely packed, the ALDC/ZII-positive cells show large nuclei, scant cytoplasm, and occasional processes (arrow). Projections of three consecutive optical sections of $40 \mu \mathrm{m}$ vibratome sections. Scale bar: $a, 175 \mu \mathrm{m} ; b, 100 \mu \mathrm{m} ; c, d, 10 \mu \mathrm{m}$.

In situ hybridization was performed using a digoxygeninlabeled probe and detected by alkaline phosphatase-conjugated anti-digoxygenin antibody. Signal appeared in the SVZ within 2 hr after application of the alkaline phosphatase substrate. There 

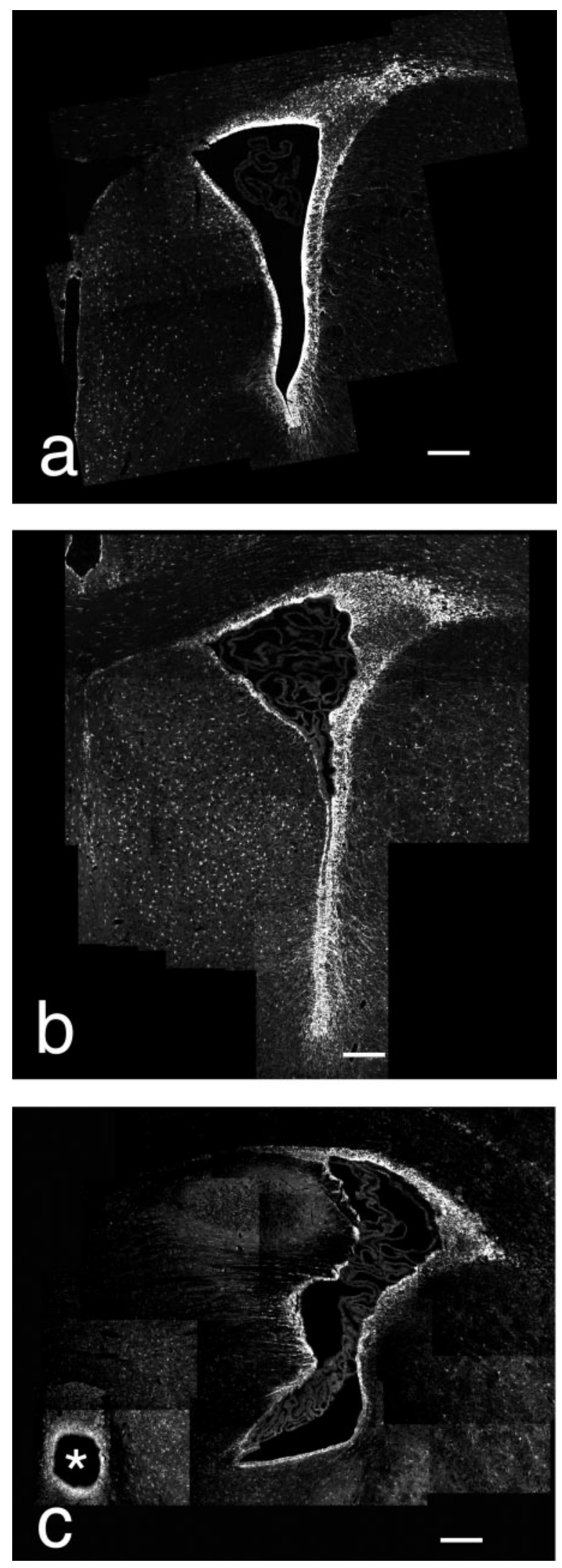

Figure 3. Pattern of ALDC/ZII immunoreactivity at three frontal levels of the SVZ. Most cells lining the ventricles are immunopositive. Increased density of ALDC/ZII-positive cells is seen at the lateral angle of the lateral ventricle and at the most dorsolateral aspect of the SVZ. Relatively more positive cells are seen subjacent to the subcortical white matter at was intense, but discontinuous, staining adjacent to the ventricles. Hybridization signal was seen in a greater proportion of the cells lining the lateral wall of the ventricle (Fig. $2 a$ ) compared with the medial wall of the ventricle (data not shown). In addition, there were two discrete areas of labeled cells within the lateral SVZ (Fig. 2a). One area appeared as a widening of the periventricular staining at the lateral angle of the lateral ventricle. The second dense area was located at the most dorsolateral aspect of the SVZ. Scattered cells between these two regions were also labeled. Several intensely labeled cells could also be seen in the white matter just dorsal to the SVZ. This general pattern of expression was seen in frontal sections at all levels of the forebrain from the anterior extent of the lateral ventricles (aSVZ) to the level of the anterior hippocampus (data not shown; but see immunocytochemistry in Fig. 3). In some cases the alkaline phosphatase substrate reaction was allowed to proceed for up to $5 \mathrm{~d}$ with daily replacement of substrate. Signal within SVZ cells intensified but showed the same distribution. In addition, labeled cells appeared in gray and white matter throughout the forebrain (data not shown; but see below). No signal was identified in sections hybridized with a sense probe (data not shown).

\section{ALDC/ZII expression in the SVZ}

Immunolocalization of ALDC/ZII expression was performed using a monoclonal antibody to ZII. The pattern of immunostaining in the SVZ corresponded with that seen by in situ hybridization (Fig. 2, compare $a, b$ ). Figure 3 shows low-power frontal images of ALDC/ZII immunostaining at the level of the genu of the corpus callosum (Fig. 3a), level of the septal nuclei (Fig. 3b), and level of the anterior hippocampus (Fig. $3 c$ ). The same general pattern of immunoreactivity of the dorsolateral SVZ was seen at these three levels. At the level of the anterior hippocampus, there was relatively more immunoreactivity subjacent to the subcortical white matter. Figure $3 c$ also shows intense immunoreactivity in the cells lining the anterior aspect of the third ventricle. Immunoreactivity of the choroid plexus was variable and was not further investigated.

The ALDC/ZII-positive cells that line the ventricle were generally columnar in morphology; however, occasionally cuboidal cells were also immunoreactive (Figs. $2 c, 4 a, b$ ). ALDC/ZIIpositive cells beneath this layer were densely packed, and the morphology of the individual cells was difficult to discern by conventional or confocal microscopy (Fig. 2c). This was also true for the cells at the most dorsolateral aspect of the SVZ. In central regions of the SVZ, where the ALDC/ZII-positive cells were more sparsely distributed, individual cells had large nuclei and scant perikaryal cytoplasm (Fig. 2d). Numerous ALDC/ZIIpositive processes were present within the SVZ (Fig. 4a, red). Occasionally, a process could be associated with a cell body (Fig. $2 d$, arrow), but generally processes coursing through the SVZ could not be associated with single cells.

The number of ALDC/ZII-immunopositive cells was quantified in sections taken at the level of the septal nuclei. At this level, ALDC/ZII-immunopositive cells represented $\sim 10 \%$ of the total

the level of the anterior hippocampus. Cells lining the anterior aspect of the third ventricle (asterisk) are also seen. $a$, Level of genu of corpus callosum; $b$, level of septal nuclei; $c$, level of anterior hippocampus. Images represent composites of 10-20 images captured using a $10 \times$ objective and incorporated into a montage using Adobe Photoshop. Scale bars, $200 \mu \mathrm{m}$. 

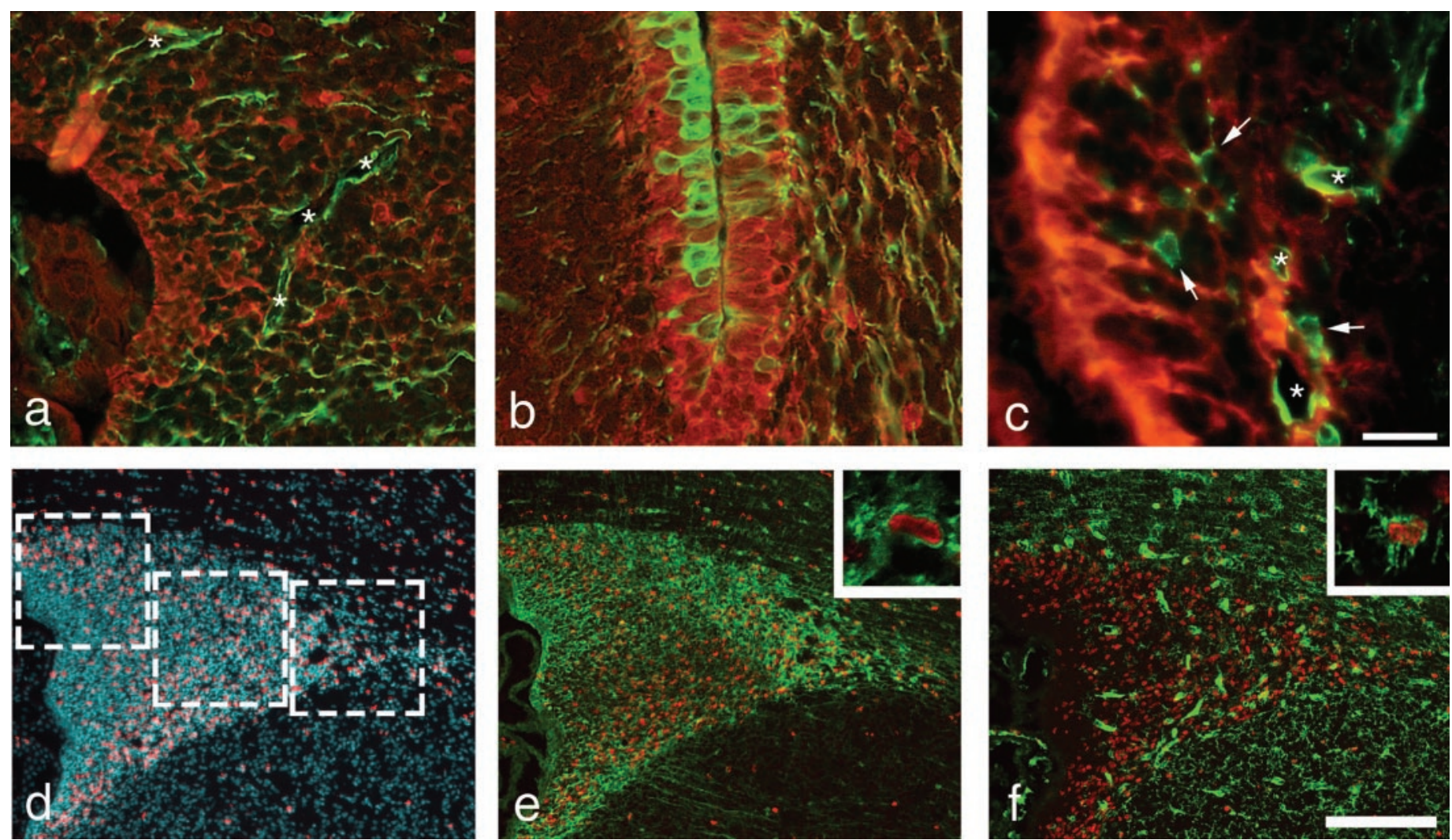

Figure 4. Immunophenotype of cells in the rat P5-P7 SVZ. a, SVZ-labeled with antibodies to ALDC/ZII (red) and vimentin (green). Numerous ALDC/ZII-positive cell bodies and processes are present. Vimentin labels processes that do not colocalize with ALDC/ZII-positive processes. Vimentin also labels blood vessels (asterisks); $7 \mu \mathrm{m}$ paraffin section. $b$, Inferior aspect of the SVZ. Most ALDC/ZII-positive cells (red) are tall-columnar, whereas most vimentin-positive cells (green) are cuboidal. In contrast to the SVZ parenchyma (a), processes in adjacent striatum (right) show colocalization of ALDC/ZII and vimentin (yellow); $7 \mu \mathrm{m}$ paraffin section. $c$, NG2-positive cells in the SVZ (green) are rare and are readily distinguished from ALDC/ZII-positive cells (red) by their round cell bodies and delicate processes. Three NG2-positive cell bodies are seen in this field (arrows). Blood vessels are also labeled with antibodies to NG2 (asterisks). Section is focused to best demonstrate the NG2-positive cells; $7 \mu \mathrm{m}$ paraffin sections. $d-f$, BrdU labeling in SVZ; $10 \mu \mathrm{m}$ cryostat sections. $d$, Representative image of an SVZ showing BrdU labeling with 4',6'-diamidino-2-phenylindole nuclear counterstain. Squares show representative areas used for quantification of labeled cells shown in Table 1. BrdU is incorporated by 6-8\% of the SVZ nuclei (Table 1). e, Double labeling for ALDC/ZII ( green) and BrdU (red). This image is the same as shown in $d$, but with green and red channels displayed. Inset shows high-power view of an ALDC/ZII-positive cell that has incorporated BrdU. $f$, Double labeling for NG2 (green) and BrdU (red). At the low magnification shown, only the NG2-labeled blood vessels are conspicuous. Inset shows a BrdU-positive, NG2-positive cell within the SVZ parenchyma. Scale bars: $a, b, 30 \mu \mathrm{m} ; c, 20 \mu \mathrm{m} ; d-f, 200 \mu \mathrm{m}$.

cell population in the dorsolateral region of the SVZ (Table 1). The density of ALDC/ZII-positive cells in the different representative areas sampled was $\sim 16$ and $14 \%$ of the total cells in the medial and lateral areas counted (Fig. $4 d$ ) and 5\% in the central area. The percentage of cells in each area counted that were single-positive for BrdU and double-positive for BrdU and ALDC/ZII was not different from the overall values reported in Table 1 ( 6 and $1 \%$, respectively).

ALDC/ZII-positive cells in the SVZ were examined for coexpression of three antigens: GFAP, vimentin, and NG2 chondroitin sulfate proteoglycan. Both GFAP and vimentin are expressed by astrocyte lineage cells. Vimentin expression typically precedes GFAP expression in astrocytes. NG2 is expressed by cycling glial cells that are abundant throughout the CNS and have properties of oligodendrocyte progenitors (Ward et al., 1991; Levine et al., 1993; Nishiyama et al., 1996a; Reynolds and Hardy, 1997). Vascular endothelial cells within the CNS also express vimentin and NG2. At 1 postnatal week, we observed no significant GFAP immunoreactivity in the SVZ (data not shown). Variable numbers of cuboidal cells lining the medial and ventral aspects of the lateral ventricles were vimentin-positive (Fig. 4b, green). The location and morphology of these vimentin-positive cells suggested that they were ependymal. Vimentin immunoreactivity did not colocalize with ALDC/ZII immunoreactivity in these cells. As noted above, most, but not all ALDC/ZII-positive cells that line the ventricle were columnar (Fig. 4b, red). These data suggest that the ALDC/ZII cells that line the ventricles may transform into ependymal cells. Antibodies to vimentin also labeled radially oriented processes coursing through the SVZ that were distinct from the ALDC/ZII-positive processes (Fig. 4a). Vimentin also demonstrated the location of blood vessels in the SVZ (Fig. 4a, asterisks). In contrast to our findings in the cortex and white matter (see below), ALDC/ZII immunoreactivity in the SVZ did not appear to ensheathe blood vessels. Antibodies to the NG2 chondroitin sulfate proteoglycan labeled $\sim 2 \%$ of the cells within the SVZ parenchyma (Fig. 4c,f, Table 1). Blood vessels were also prominently stained with this antibody (Fig. $4 c$, asterisks). The NG2-positive cells in the SVZ parenchyma had round cell bodies and a few thin processes (Fig. 4c, $f$ ). No NG2-positive cells were seen at the ventricular surface, and double-labeling for NG2 and ALDC/ZII showed no colocalization of these two antigens (Fig. 4c). 


\begin{tabular}{ll}
\hline \multicolumn{2}{l}{ Table 1. Immunophenotype of cells in P5 rat SVZ } \\
\begin{tabular}{lll} 
Immunophenotype & Number of cells & \\
\hline $\begin{array}{l}\text { Single-labeled cells } \\
\text { ALDC/ZII }\end{array}$ & 544 & $\begin{array}{l}(10 \% \text { of total }) \\
(2 \% \text { of total })\end{array}$ \\
NG2 & 110 & \\
BrdU & 334 (ALDC/ZII) & $(6-8 \%$ of total $)$ \\
& $471(\mathrm{NG} 2)$ & \\
Double-labeled cells & $47 / 334$ & $(14 \%$ of BrdU-positive $)$ \\
ALDC/ZII and BrdU & $47 / 544$ & $(9 \%$ of ALDC/ZII-positive $)$ \\
& $47 / 5281$ & $(1 \%$ of total $)$ \\
& $19 / 471$ & $(4 \%$ of BrdU-positive $)$ \\
NG2 and BrdU & $19 / 110$ & $(17 \%$ of NG2-positive $)$ \\
& $19 / 5790$ & $(0.3 \%$ of total $)$
\end{tabular}
\end{tabular}

Double-label immunofluorescence using antibodies to BrdU and ALDC/ZII or NG2 was performed on sections from P5 rats that received intraperitoneal injections of BrdU at 4 and $2 \mathrm{hr}$ before perfusion. The data in this table reflect the number of labeled cells counted in two representative SVZs for each set of antibody stains. Images from three nonoverlapping confocal fields, representing the medial, central, and lateral aspects of the each dorsolateral SVZ, were collected (Fig. 4d), and the total number of single- and double-labeled cells was counted. The data are analyzed from three perspectives: the number of single- or double-labeled cells as proportion of (1) total nucleated cells, (2) total BrdU-positive cells, and (3) total ALDC/ZII- or NG2-positive cells. The total SVZ area analyzed was $2.8 \times 10^{5} \mu \mathrm{m}^{2}$ for ALDC/ZII-stained sections and $3.1 \times 10^{5} \mu \mathrm{m}^{2}$ for NG2. Representative DAPI-stained sections were scanned to determine the average number of nuclei per unit area so that the total number of cells within the areas counted could be estimated. This equaled 5281 for ALDC/ZII staining and 5790 for NG2 staining.

The potential for ALDC/ZII-positive cells and NG2-positive cells of the SVZ to synthesize DNA was assessed by BrdU labeling in vivo. P5 rat pups were injected with BrdU 4 and $2 \mathrm{hr}$ before intracardiac perfusion. Using this labeling paradigm, 6-8\% of the total cell population in the SVZ was BrdU-positive (Table 1, Fig. $4 d$, red). BrdU-positive cells were uniformly distributed throughout most of the dorsolateral SVZ; however the BrdUpositive cells were relatively rare in the cells adjacent to the ventricle. Both ALDC/ZII-positive and NG2-positive cells in the SVZ showed evidence of BrdU incorporation (Fig. 4e,f). A total of $14 \%$ of BrdU-positive cells were ALDC/ZII-positive, and 4\% were NG2-positive (Table 1). Therefore, ALDC/ZII-positive and NG2-positive cells represent a relatively small proportion of the proliferating cells in the SVZ at 5 postnatal days. BrdU-positive nuclei were observed in $9 \%$ of the ALDC/ZII-positive cells and $17 \%$ of the NG2-positive cells. As a population, the ALDC/ZIIpositive cells have a BrdU-labeling index that is similar to the total population of cells in the SVZ (9 vs 6-8\%), whereas the BrdU-labeling index of NG2-positive cells is relatively greater.

\section{ALDC/ZII expression in the gray and white matter}

Widespread ALDC/ZII immunoreactivity was seen in the gray and white matter (Fig. $5 a$ ), however the fluorescence intensity was much less than that seen in the SVZ (compare Fig. 3). High magnification showed that these cells had one or more thick processes that branched (Fig. $5 b-d$ ). In gray matter the cell bodies were round or polygonal (Fig. $5 b, c$ ), whereas in white matter the cell bodies were more elongated (Fig. $5 d$ ). Frequently a process extended to a blood vessel and appeared to ensheathe the vessel in immunoreactivity (Fig. 5e). No cells with a neuronal morphology reacted with antibodies to ALDC/ZII.

The morphology of ALDC/ZII-expressing cells and their frequent association with blood vessels suggested that these cells were differentiating astrocytes. We examined this possibility by double labeling sections with antibodies to vimentin or GFAP. Vimentin immunoreactivity was present in radially oriented cell processes and in process-bearing parenchymal cells. In the gray and white matter, we observed extensive colocalization of ALDC/ZII and vimentin immunoreactivity (Fig. $6 a-f$ ). In general, the cells in white matter were more intensely labeled by both vimentin and ALDC/ZII antibodies than the cells in gray matter. Rare ALDC/ZII-positive cells did not label with vimentin (Fig. $6 a, d)$. These vimentin-negative cells had simple, unipolar morphologies, characteristic of immature migratory cells, and did not appear to contact blood vessels. By contrast, cells double-labeled with antibodies to ALDC/ZII and vimentin typically had two or more vimentin-immunoreactive processes (Fig. 6b,c,e,f).

Numerous cells in gray and white matter were also doublelabeled with antibodies to ALDC/ZII and GFAP, but some were not. Figure $6, g$ and $j$, shows a field with only one identifiable ALDC/ZII-positive cell body (arrow) that is GFAP-negative. The blood vessel in the center of the field shows immunoreactivity with both antibodies. This represents labeling of the perivascular endfeet of astrocytes; the cells bodies associated with these processes are out of the plane of focus. Vascular endothelial cells did not label with antibodies to ALDC/ZII or GFAP. Figure $6, h$ and $k$, shows multiple double-labeled cell bodies, whereas Figure $6, i$ and $l$, shows that only one of the multiple GFAP-positive cells present in this field is strongly ALDC/ZII-positive.

The number of ALDC/ZII-positive cells that were also immunoreactive with antibodies to vimentin and/or GFAP was examined in triple-labeled sections. Table 2 shows quantitation of cells in gray and white matter areas in a representative section. A total of $98-100 \%$ of ALDC/ZII-positive cells in corpus callosum and cingulum were also vimentin- or GFAP-positive. In the anterior limbic region of the medial frontal cortex, the percentage of ALDC/ZII-positive cells that were also vimentin- or GFAPpositive was slightly less ( 88 and $91 \%$, respectively). The intensity of ALDC/ZII immunoreactivity was similar in all regions examined, whereas the intensity of vimentin and GFAP immunoreactivity varied. Both vimentin and GFAP immunoreactivity were very strong in the cingulum and near the pial surface, and relatively weak, but still detectable in deep cortex (data not shown). 

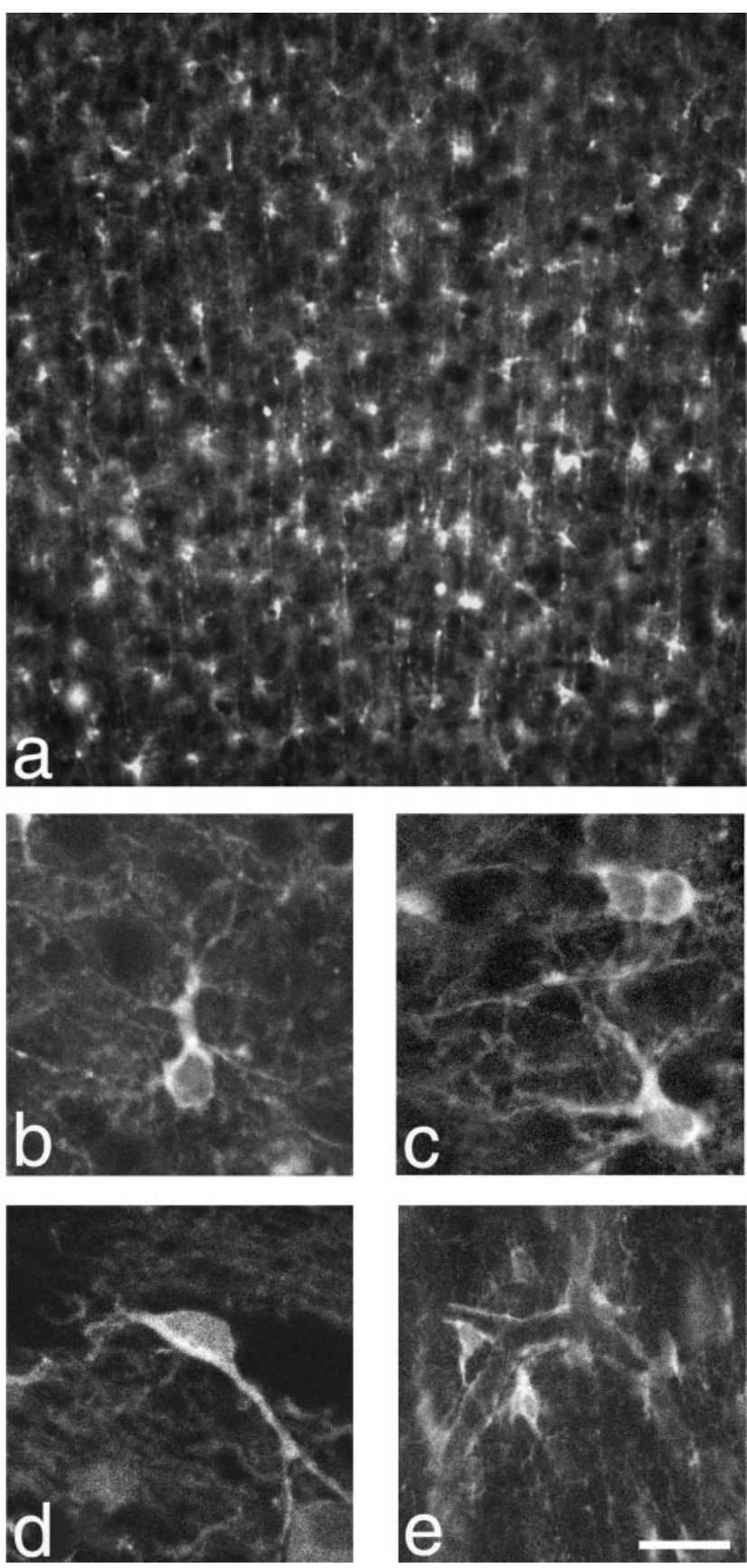

Figure 5. Immunofluorescence labeling of rat P5-P7 cerebral cortex and subcortical white matter with antibodies to ALDC/ZII. a, Lowmagnification photomicrograph of cerebral cortex demonstrates numerous immunopositive cells and radially oriented fibers that extend to the pial surface. $b, c$, High-power photomicrographs of ALDC/ZII-positive cells in cerebral cortex. The cells have round, unstained nuclei, polygonal cell bodies, and one or more thick processes that branch. $d$, ALDC/ZIIpositive cells in white matter have a more elongated morphology than cells in gray matter. $e$, ALDC/ZII-positive cells in white matter associate with blood vessels that appear ensheathed in immunoreactivity; $40 \mu \mathrm{m}$ vibratome sections. $a$, Conventional epifluorescence; $b-e$, confocal projection of three optical sections. Scale bar: $a, 50 \mu \mathrm{m} ; b-d, 15 \mu \mathrm{m} ; e, 30 \mu \mathrm{m}$.

The possibility that cells expressing ALDC/ZII might also be expressed by cells of early oligodendrocyte lineage was tested by double labeling sections with antibodies to ALDC/ZII and NG2. No coexpression of ALDC/ZII and NG2 was seen in $>500$ cells examined (Fig. 7a,b).

\section{Origin of ALDC/ZII-positive and NG2-positive cells in white and gray matter}

We showed earlier (Table 1, Fig. $4 d-f$ ) that ALDC/ZII-positive and NG2-positive cells are present in the postnatal SVZ and show evidence of DNA synthesis. We asked whether these cells were precursors to the numerous ALDC/ZII-positive and NG2positive cells in the gray and white matter by lineage tracing using the BAG retrovirus. Previously, we have shown that when the $\mathrm{BAG}$ virus is injected into the $\mathrm{SVZ}$ at $\mathrm{P} 0-\mathrm{P} 1$ and the brains are examined for $\beta$-galactosidase expression $5 \mathrm{~d}$ later, undifferentiated unipolar and bipolar cells, as well as differentiated astrocytes and oligodendrocytes, could be recognized (Levison and Goldman, 1993; Zerlin et al., 1995). We stained a total of forty vibratome sections from four different BAG-injected brains with antibodies to $\beta$-galactosidase and either ALDC/ZII or NG2. A total of $377 \beta$-galactosidase-positive cells were identified. Table 3 shows that $65 \%$ of the $\beta$-galactosidase-labeled cells were present in the SVZ at $5 \mathrm{~d}$ after injection. None of these cells labeled with ALDC/ZII, and only three labeled with NG2. This is compatible with the relatively low labeling indices that we obtained for both of these populations with BrdU labeling (Table 1).

At $5 \mathrm{~d}$ after injection, $21 \%$ of the $\beta$-galactosidase-positive cells were present in cerebral cortex, and $14 \%$ were present in subcortical white matter, indicating that these cells (or their progenitors) had migrated out of the SVZ since the time of injection. $\beta$-galactosidase-positive cells in gray and white matter demonstrated a variety of morphologic phenotypes ranging from immatureappearing unipolar cells to multiprocess astrocytes and premyelinating oligodendrocytes. Cells expressing both $\beta$-galactosidase and ALDC/ZII were more numerous in the cortex than in the white matter (Table 3 ). Figure 7, $c$ and $d$, shows a cluster of three cells that double label. One is unipolar and two have several processes. Both of the multiprocess cells contact a blood vessel. Sections stained with $\beta$-galactosidase and NG2 antibodies showed doublelabeled cells in both cortex and white matter also, but these were more frequently found in white matter (Table 3). Both simple and multiprocess-bearing cells were also seen. The NG2-positive cells did not extended their processes to blood vessels, nor did they demonstrate the morphologic characteristics of myelinating oligodendrocytes (data not shown).

\section{DISCUSSION}

\section{Heterogeneity of the neonatal SVZ}

The SVZ of the lateral ventricle is a densely cellular structure that expands rapidly in the perinatal period. It is the birthplace of cells that migrate into the forebrain to form glia during development (Levison and Goldman, 1993) and certain populations of neurons in the adult (Lois and Alvarez-Buylla, 1993; Chiasson et al., 1999). From the time of its appearance in late gestation and throughout postnatal life, this region contains the greatest concentration of proliferating cells in the forebrain. Early investigators described these cells in terms of nuclear morphology and ${ }^{3} \mathrm{H}$-thymidine incorporation. Most of the cells had small dark nuclei and were most likely to show evidence of DNA synthesis; the remaining cells had large pale nuclei and, less commonly, also incorporated ${ }^{3} \mathrm{H}$-thymidine. Quantitative DNA labeling studies suggest that SVZ cells cycle at different rates, and the overall length of the cell cycle increases during development (Takahashi et al., 1995). Furthermore, it has been suggested that selfrenewing stem cells in the SVZ are likely to cycle more slowly than more restricted progenitors that emigrate (Doetsch et al., 1997). 

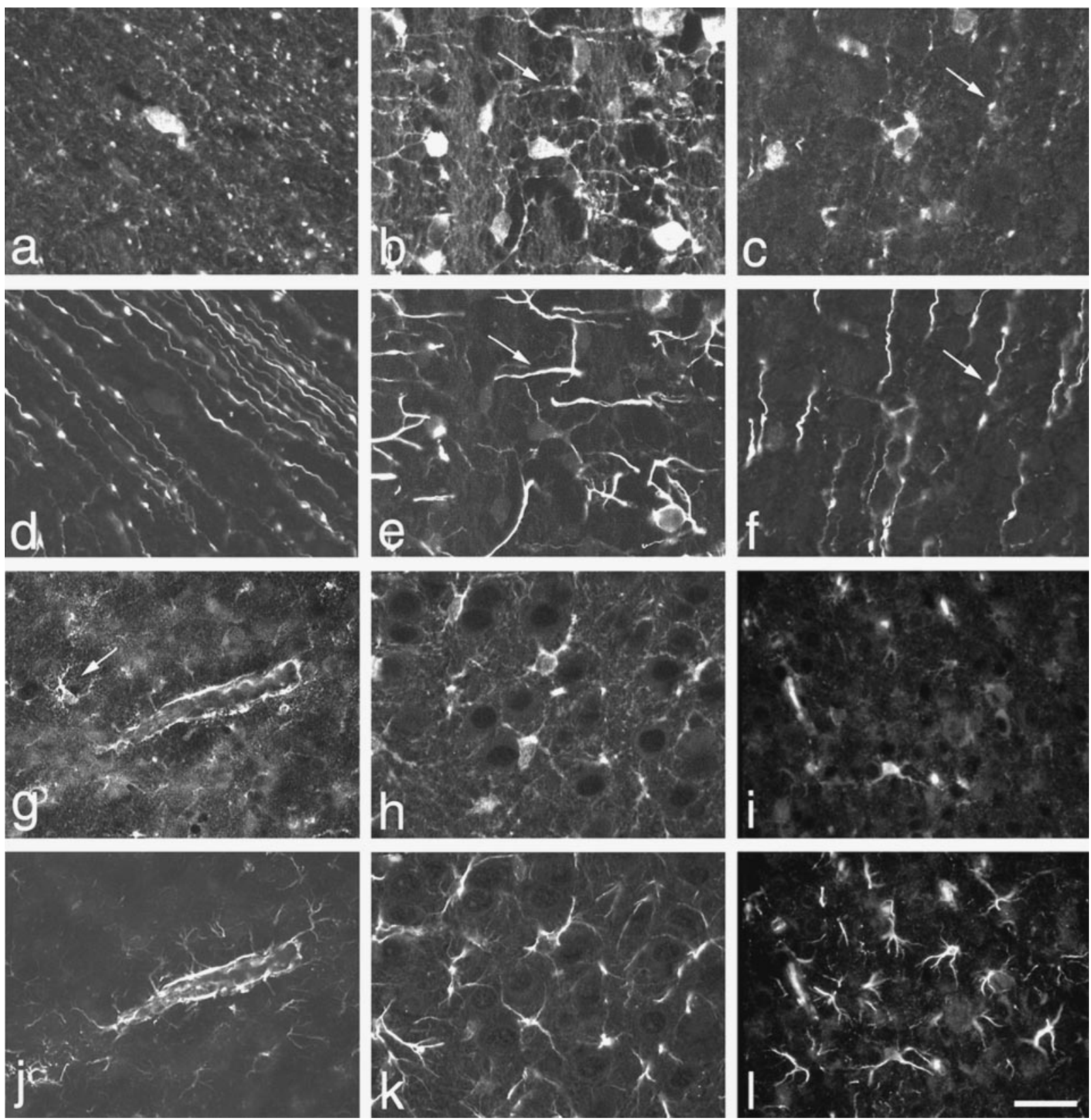

Figure 6. Many ALDC/ZII-positive cells in rat P5-P7 forebrain coexpress vimentin and GFAP. $a-f$, Double immunofluorescence labeling with antibodies to ALDC/ZII $(a-c)$ and vimentin $(d-f) . a, d$, Rare ALDC/ZII-positive cells are vimentin-negative. Most ALDC/ZII-positive cells in white matter $(b, e)$ and cerebral cortex $(c, f)$ have weak vimentin immunoreactivity in their cell bodies and processes. In addition, many processes that could not be traced to cell bodies show intense vimentin labeling and punctate ALDC/ZII labeling (arrows). $g$-l, Double immunofluorescence labeling with antibodies to ALDC/ZII $(g-i)$ and GFAP $(j-l)$. Some ALDC/ZII-positive cells $(g$, arrow $)$ are GFAP-negative $(j)$. Double-labeled processes frequently surrounded blood vessels $(g, j)$. Cell bodies associated with these processes are not in the plane of focus. $h, k$, Field showing extensive colocalization of ALDC/ZII and GFAP labeling. $i$, $l$, Occasionally, cells with intense GFAP immunoreactivity $(l)$ do not show significant ALDC/ZII immunoreactivity (i); $7 \mu \mathrm{m}$ paraffin sections. Scale bar: $a, d, 10 \mu \mathrm{m} ; b, c, e, f, h, k, 12 \mu \mathrm{m} ; g, j, 20 \mu \mathrm{m} ; i, l, 60 \mu \mathrm{m}$.

In this paper, we have used markers of cellular proliferation and lineage to characterize the expression of ALDC/ZII and $\mathrm{NG} 2$ in the SVZ. Our work demonstrates that, despite its relative histologic uniformity, the SVZ is composed of subpopulations of cells that can be characterized by their proliferative capacity and spatial distributions. This extends previously published data describing other antigenically defined subpopulations of cells in the neonatal and adult SVZ (Gates et al., 1995; Doetsch et al., 1997). Although the perinatal and adult SVZ may be quite different, the general functional importance of heterogeneity is that a nonran- dom distribution of different cell types within the SVZ may permit the formation of microenvironments that stimulate the production of cells with specific potentials at appropriate points in development.

A small percentage of SVZ cells that express ALDC/ZII or NG2 incorporate BrdU after a short labeling period. Although this indicates that both of these cell populations are cycling, neither population shows significant expression of a retroviral marker injected directly into the SVZ at birth. BrdU is systemically injected and is available for incorporation into all cells that 
Table 2. Quantitation of ALDC/ZII-positive cells that coexpress vimentin and GFAP in cortex and white matter of P5-P7 forebrain

\begin{tabular}{lllllll} 
Region & ALDC/ZII+ cells & $\begin{array}{l}\text { Area counted } \\
\left(\mu \mathrm{m}^{2}\right)\end{array}$ & $\begin{array}{l}\text { ALDC/ZII+ } \\
\text { cells/100 } \mu \mathrm{m}^{2}\end{array}$ & $\begin{array}{l}\text { ALDC/ZII+ } \\
\text { Vimentin+ }\end{array}$ & $\begin{array}{l}\text { ALDC/ZII+ } \\
\text { GFAP+ }\end{array}$ & $\begin{array}{l}\text { ALDC/ZII+ } \\
\text { Vimentin+ GFAP+ }\end{array}$ \\
\hline Cortex & 188 & 785 & 23.9 & $165(88 \%)$ & $172(91 \%)$ & $155(82 \%)$ \\
White matter & 167 & 686 & 24.3 & $163(98 \%)$ & $167(100 \%)$ & $163(98 \%)$ \\
\hline
\end{tabular}

Cortex, Medial frontal cortex (anterior limbic area); White matter, corpus callosum and cingulum.

synthesize DNA, whereas the number of cells capable of retroviral integration is dependent on the titer of the virus injected and the proximity of the cycling cells to the virus. Neither of these measurements indicate how rapidly individual cells are cycling. For example, if all members of the population under examination share identical growth kinetics, a labeling index of $9 \%$ would indicate that the cells are cycling relatively slowly. However, the same labeling index would also be observed if the majority of the cells were quiescent and a small subset of the cells were cycling rapidly.

A slowly dividing population might serve as a self-renewing progenitor (stem cell) to cells that divide rapidly, are highly susceptible to retrovirus incorporation, and ultimately migrate out of the SVZ. Although this model is plausible for the SVZ cells that express ALDC/ZII, we would have to postulate that this transition is associated with rapid downregulation of their expression of ALDC/ZII. Another possibility is that ALDC/ZIIpositive cells are nonmigratory cells that provide a supportive function by production of growth factors that stimulate maturation and migration of other cells.

Doetsch et al. (1997) have described a population of dividing
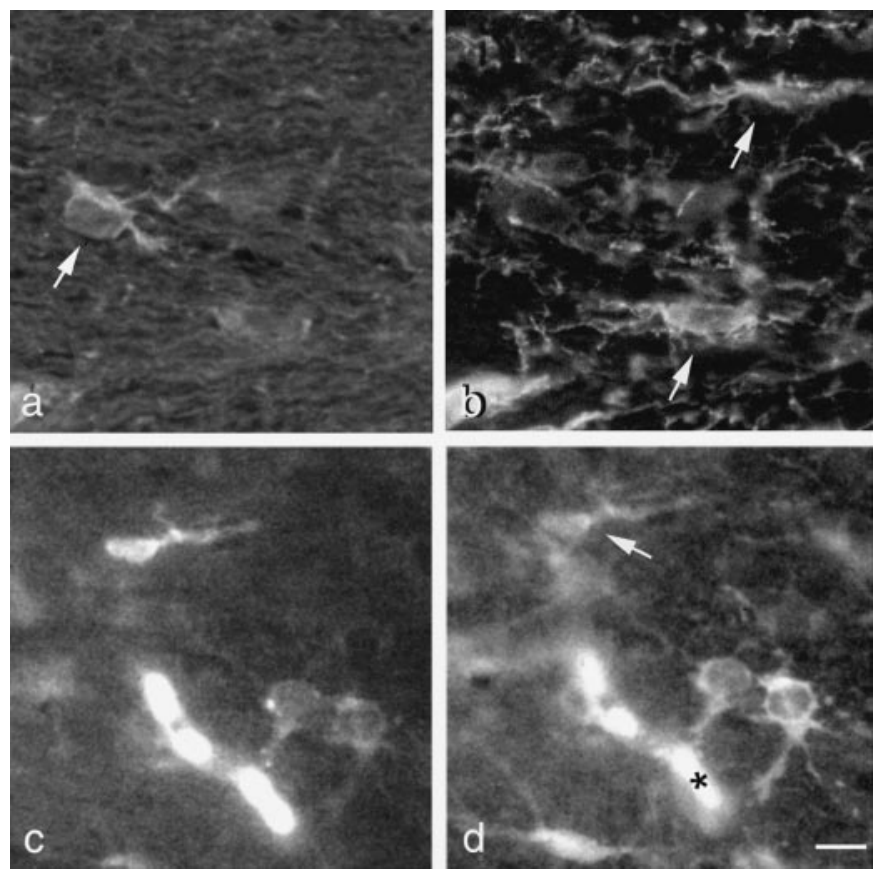

Figure 7. Double immunofluorescence labeling of ALDC/ZII and NG2 or $\beta$-galactosidase. $a, b$, Immunolabeling for ALDC/ZII $(a)$ and NG2 $(b)$ in white matter. ALDC/ZII and NG2 antibodies label different cells (arrows); $7 \mu \mathrm{m}$ paraffin section. $c, d$, Immunolabeling for $\beta$-galactosidase $(c)$ and $\mathrm{ALDC} / \mathrm{ZII}(d)$ in a rat injected with the BAG retrovirus at $\mathrm{P} 0$ and analyzed $5 \mathrm{~d}$ after injection. Three $\beta$-galactosidase-positive cells in cortex are also ALDC/ZII-positive. Two of the cells extend processes to a capillary (asterisk in $d$ ). Erythrocytes within the capillary show nonspecific fluorescence; $40 \mu \mathrm{m}$ vibratome section. Scale bar: $a, b, 7 \mu \mathrm{m} ; c, d, 12 \mu \mathrm{m}$. cells in the adult SVZ that express GFAP and are interpreted by the authors as astrocytes. Although we clearly show that ALDC/ ZII is expressed by astrocytes of the neonatal gray and white matter, we do not interpret the ALDC/ZII-positive cells in the SVZ as such because they do not express vimentin or GFAP and do not ensheathe blood vessels. In any case, the ALDC/ZII cells may correspond to the "light cells" described by Smart (1961). Both of these populations had relatively large nuclei and comprised $10 \%$ of the SVZ population.

\section{ALDC/ZII expression during astrocyte differentiation}

Astrocytes have a stellate morphology and characteristically send out endfeet that ensheathe capillaries. In the cerebral cortex and white matter, the ZII monoclonal antibody labels cells with this morphology and confirms previous observations using antibodies to aldolase C (Thompson et al., 1982; Kumanishi et al., 1985; Brochu et al., 1990). Our data extend these results by demonstrating the coexpression of ALDC/ZII with other antigens expressed by astrocytes, such as vimentin and GFAP.

ALDC/ZII-positive cells in cortex and white matter may also have a unipolar phenotype and show no association with blood vessels. This phenotype is commonly seen in actively migrating progenitor cells arising from the SVZ (Kakita and Goldman, 1999). Our retroviral labeling studies showed that some of the unipolar $\beta$-galactosidase-positive cells, which had emigrated from the SVZ, were ALDC/ZII-immunopositive, whereas the $\beta$-galactosidase-positive cells within the SVZ were ALDC/ZIIimmunonegative. These data indicate that detectable levels of ALDC/ZII protein were acquired by the $\beta$-galactosidase-positive cells after exit from the SVZ. However, it is possible that the onset of ALDC/ZII mRNA synthesis occurs before exit. Unipolar SVZ progenitors that contact blood vessels in cerebral cortex express vimentin (Zerlin et al., 1995) and support the notion that vimentin expression occurs very early in the differentiation of astrocytes. These data, along with our observation that the majority of ALDC/ ZII-positive cells coexpress vimentin raise the possibility that the unipolar ALDC/ZII-positive cells in cortex and white matter that do not contact blood vessels represent an earlier stage in the astrocyte lineage.

Table 3. Immunophenotype of BAG-expressing cells at $5 \mathrm{~d}$ after injection

\begin{tabular}{lccl} 
Region & Total BAG + & ALDC/ZII + & NG2 + \\
\hline SVZ & $245(65 \%)$ & $0 / 101$ & $3 / 144$ \\
SCWM & $52(14 \%)$ & $5 / 36$ & $9 / 16$ \\
Cortex & $80(21 \%)$ & $14 / 40$ & $4 / 40$
\end{tabular}

$\%=$ percentage of total $\mathrm{BAG}+$ cells for all three regions. A total of $377 \mathrm{BAG}+$ cells were analyzed. One hundred seventy-seven were present in sections doublelabeled with ALDC/ZII, and 200 were in sections double-labeled with NG2. SVZ, Subventricular zone; SCWM, subcortical white matter. 


\section{ALDC/ZII-positive cells are distinct from NG2-positive oligodendrocyte progenitors}

In this study, we have also compared the expression of ALDC/ ZII with the NG2 chondroitin sulfate proteoglycan. NG2 is expressed by glial cells that appear early in development and are present in large numbers in the adult brain (Levine et al., 1993; Levine and Nishiyama, 1996; Nishiyama et al., 1996a). In vitro, NG2-positive cells have properties of oligodendrocyte progenitors (Levine and Stallcup, 1987; Nishiyama et al., 1996b), and in vivo a proportion of these cells coexpress the O4 antigen (Reynolds and Hardy, 1997). During periods of rapid myelination, rare NG2-positive cells also react with antibodies to galactocerebroside (Levine et al., 1993) and the DM20/proteolipid protein (Trapp et al., 1997), providing an additional link between glial cells bearing the NG2 antigen and the oligodendrocyte lineage. There is no evidence of GFAP expression by NG2-positive cells in vivo, even after injury (Levine, 1994; Nishiyama et al., 1997; Ong and Levine, 1999). We find that mutually exclusive populations of cells express NG2 and ALDC/ZII. Although this suggests that the majority of cells expressing these two antigens are of separate lineages, we cannot rule out the possibility that a unipolar cell committed to a specific lineage can express either NG2 or ALDC/ZII sequentially. NG2 expression was seen in few $\beta$-galactosidase-positive progenitor cells within the SVZ 1 week after BAG virus injection, suggesting the possibility that some SVZ progenitors acquire NG2 immunoreactivity before exiting the SVZ. Although this observation needs to be investigated in more detail, it is clear that the vast majority of cells that emigrate from the SVZ acquire immunoreactivity to ALDC/ZII or NG2 after exit from this region.

\section{Glial fate restriction}

Numerous studies in the past 20 years have suggested that a bipotential glial progenitor cell gives rise to both astrocytes and oligodendrocytes. The evidence is largely based on cell culture (Raff et al., 1983; Lee et al. 2000); however, lineage tracing analysis of clones obtained by injection of single recombinant retroviruses (Levison and Goldman, 1993) or libraries of $>100$ genetically different recombinant viruses (M. Zerlin and J. E. Goldman, unpublished observations) have provided compelling evidence that individual progenitors within the SVZ are bipotential. These data suggest that glial fate restriction in vivo occurs after bipotential cells exit the SVZ. Our data show that cells with morphology of migrating progenitors demonstrate at least two different immunophenotypes associated with different glial lineages. If expression of either ALDC/ZII or NG2 proves to signal fate restriction of bipotential progenitors, this would indicate that this choice is made during migration. When and why one or more progeny of a single cell makes the choice to become an astrocyte rather than an oligodendrocyte remains a challenging question, but, with recent advances in expression of fluorescent transgenes by lineage-specific promoters, real time imaging of dynamic events in living tissues, and sensitive molecular techniques to characterize gene expression in single cells, answers to these questions are now within our reach.

\section{Conclusions}

ALDC/ZII is expressed by different types of non-neuronal cells within the neonatal rat forebrain. It is clearly expressed by astrocytes as defined as cells that display vimentin and GFAP expression and vascular association. In addition, it is expressed by morphologically undifferentiated unipolar cells in gray and white matter that may or may not be determined to be astrocytes. ALDC/ZII is also expressed by cells within specific subdomains of the SVZ. They show evidence of proliferation by BrdU incorporation, but they do not constitute the major population of cells that incorporate retrovirus and migrate out of the SVZ. Finally, they are not astrocytes by the criteria defined above. The specific function of aldolase $\mathrm{C}$ in these different cell populations is unknown. Because aldolase activity is critical to glucose metabolism, increased expression of this gene may reflect the metabolic state of these different subpopulations of cells.

\section{REFERENCES}

Ahn AH, Dziennis S, Hawkes R, Herrup K (1994) The cloning of zebrin II reveals its identity with aldolase C. Development 120:2081-2090.

Arai Y, Kajihara S, Masuda J, Ohishi S, Zen K, Ogata J, Mukai T (1994) Position-independent, high-level, and correct regional expression of the rat aldolase $\mathrm{C}$ gene in the central nervous system of transgenic mice. Eur J Biochem 221:253-260.

Brochu G, Maler L, Hawkes R (1990) Zebrin II: a polypeptide antigen expressed selectively by Purkinje cells reveals compartments in rat and fish cerebellum. J Comp Neurol 291:538-552.

Chiasson BJ, Tropepe V, Morshead CM, van der Kooy D (1999) Adult mammalian forebrain ependymal and subependymal cells demonstrate proliferative potential, but only subependymal cells have neural stem cell characteristics. J Neurosci 19:4462-4471.

Chiu FC, Goldman JE (1984) Synthesis and turnover of cytoskeletal proteins in cultured astrocytes. J Neurochem 42:166-174.

Doetsch F, Garcia-Verdugo JM, Alvarez-Buylla A (1997) Cellular composition and three-dimensional organization of the subventricular germinal zone in the adult mammalian brain. J Neurosci 17:5046-5061.

Gates MA, Thomas LB, Howard EM, Laywell ED, Sajin B, Faissner A, Gotz B, Silver J, Steindler DA (1995) Cell and molecular analysis of the developing and adult mouse subventricular zone of the cerebral hemispheres. J Comp Neurol 361:249-266.

Kakita A, Goldman JE (1999) Patterns and dynamics of SVZ cell migration in the postnatal forebrain: monitoring living progenitors in slice preparations. Neuron 23:461-472.

Kukita A, Mukai T, Miyata T, Hori K (1988) The structure of brainspecific rat aldolase $\mathrm{C}$ mRNA and the evolution of aldolase isozyme genes. Eur J Biochem 171:471-478.

Kumanishi T, Watabe K, Washiyama K (1985) An immunohistochemical study of aldolase $\mathrm{C}$ in normal and neoplastic nervous tissues. Acta Neuropathol (Berl) 67:309-314.

Lebherz HG, Rutter WJ (1969) Distribution of fructose diphosphate aldolase variants in biological systems. Biochemistry 8:109-121.

Lee JC, Mayer-Proschel M, Rao MS (2000) Gliogenesis in the central nervous system. Glia 30:105-121.

Levine JM (1994) Increased expression of the NG2 chondroitin-sulfate proteoglycan after brain injury. J Neurosci 14:4716-4730.

Levine JM, Nishiyama A (1996) The NG2 chondroitin sulfate proteoglycan: a multifunctional proteoglycan associated with immature cells. Perspect Dev Neurobiol 3:245-259.

Levine JM, Stallcup WB (1987) Plasticity of developing cerebellar cells in vitro studied with antibodies against the NG2 antigen. J Neurosci 7:2721-2731.

Levine JM, Stincone F, Lee YS (1993) Development and differentiation of glial precursor cells in the rat cerebellum. Glia 7:307-321.

Levison SW, Goldman JE (1993) Both oligodendrocytes and astrocytes develop from progenitors in the subventricular zone of post natal rat forebrain. Neuron 10:201-212.

Levison SW, McCarthy KD, Goslin K (1990) Astroglia in culture. In: Culturing nerve cells (Banker G, ed), pp 309-336. Cambridge, MA: MIT Press.

Lois C, Alvarez-Buylla A (1993) Proliferating subventricular zone cells in the adult mammalian forebrain can differentiate into neurons and glia. Proc Natl Acad Sci USA 90:2074-2077.

McCarthy KD, de Vellis J (1980) Preparation of separate astroglial and oligodendroglial cell cultures from rat cerebral tissue. J Cell Biol 85:890-902.

Morgan JM, Navabi H, Schmid KW, Jasani B (1994) Possible role of tissue-bound calcium ions in citrate-mediated high-temperature antigen retrieval. J Pathol 174:301-307.

Nishiyama A, Lin XH, Giese N, Heldin CH, Stallcup WB (1996a) Co-localization of NG2 proteoglycan and PDGF alpha-receptor on $\mathrm{O} 2 \mathrm{~A}$ progenitor cells in the developing rat brain. J Neurosci Res 43:299-314.

Nishiyama A, Lin XH, Giese N, Heldin CH, Stallcup WB (1996b) Interaction between NG2 proteoglycan and PDGF alpha-receptor on $\mathrm{O} 2 \mathrm{~A}$ progenitor cells is required for optimal response to PDGF. J Neurosci Res 43:315-330. 
Nishiyama A, Yu M, Drazba JA, Tuohy VK (1997) Normal and reactive $\mathrm{NG}^{2+}$ glial cells are distinct from resting and activated microglia. J Neurosci Res 48:299-312.

Ong WY, Levine JM (1999) A light and electron microscopic study of NG2 chondroitin sulfate proteoglycan-positive oligodendrocyte precursor cells in the normal and kainate-lesioned rat hippocampus. Neuroscience 92:83-95.

Privat A (1975) Postnatal gliogenesis in the mammalian brain. Int Rev Cytol 40:281-323.

Raff MC, Miller RH, Noble M (1983) A glial progenitor cell that develops in vitro into an astrocyte or an oligodendrocyte depending on the culture medium. Nature 303:390-396.

Reynolds R, Hardy R (1997) Oligodendroglial progenitors labeled with the $\mathrm{O} 4$ antibody persist in the adult rat cerebral cortex in vivo. J Neurosci Res 47:455-470.

Sambrook J, Fritsch EF, Maniatis T (1992) Molecular cloning: a laboratory manual. Cold Spring Harbor, NY: Cold Spring Harbor Laboratory.

Schaeren-Wiemers N, Gerfin-Moser A (1993) A single protocol to detect transcripts of various types and expression levels in neural tissue and cultured cells: in situ hybridization using digoxygenin-labelled cRNA probes. Histochemistry 100:431-440.

Smart I (1961) The subependymal layer of the mouse brain and its cell production as shown by radioautography after thymidine- $\mathrm{H}^{3}$ injection. J Comp Neurol 116:325-367.

Takahashi T, Nowakowski RS, Caviness VS (1995) Early ontogeny of the secondary proliferative population of the embryonic murine cerebral wall. J Neurosci 15:6058-6068.

Thompson RJ, Kynoch PA, Willson VJ (1982) Cellular localization of aldolase C subunits in human brain. Brain Res 232:489-493.

Trapp BD, Nishiyama A, Cheng D, Macklin W (1997) Differentiation and death of premyelinating oligodendrocytes in developing rodent brain. J Cell Biol 137:459-468.

Walther EU, Dichgans M, Maricich SM, Romito RR, Yang F, Dziennis S, Zackson S, Hawkes R, Herrup K (1998) Genomic sequences of aldolase C (Zebrin II) direct lacZ expression exclusively in non-neuronal cells of transgenic mice. Proc Natl Acad Sci USA 95:2615-2620.

Ward SA, Ransom PA, Booth PL, Thomas WE (1991) Characterization of ramified microglia in tissue culture: pinocytosis and motility. J Neurosci Res 29:13-28.

Welsh J, Chada K, Dalal SS, Cheng R, Ralph D, McClelland M (1992) Arbitrarily primed PCR fingerprinting of RNA. Nucleic Acids Res 20:4965-4970.

Yatsuki H, Outida M, Atsuchi Y, Mukai T, Shiokawa K, Hori K (1998) Cloning of the Xenopus laevis aldolase $\mathrm{C}$ gene and analysis of its promoter function in developing Xenopus embryos and A6 cells. Biochim Biophys Acta 1442:199-217.

Zerlin M, Levison SW, Goldman JE (1995) Early patterns of migration, morphogenesis, and intermediate filament expression of subventricular zone cells in the postnatal rat forebrain. J Neurosci 15:7238-7249. 